\title{
Corganiser: a web-based software tool for planning time-sensitive sampling of whole rounds during scientific drilling
}

\author{
I. P. G. Marshall \\ Center for Geomicrobiology, Department of Bioscience, Aarhus University, Aarhus, Denmark \\ Correspondence to: I. P. G. Marshall (ianpgm@biology.au.dk)
}

Received: 7 May 2014 - Revised: 15 July 2014 - Accepted: 12 August 2014 - Published: 22 December 2014

\begin{abstract}
Corganiser is a software tool developed to simplify the process of preparing whole-round sampling plans for time-sensitive microbiology and geochemistry sampling during scientific drilling. It was developed during the Integrated Ocean Drilling Program (IODP) Expedition 347, but is designed to work with a wide range of core and section configurations and can thus be used in future drilling projects. Corganiser is written in the Python programming language and is implemented both as a graphical web interface and command-line interface. It can be accessed online at http://130.226.247.137/.
\end{abstract}

\section{Introduction}

Modern scientific drilling projects, such as those carried out by the Integrated Ocean Drilling Program (IODP) and the International Continental Scientific Drilling Program (ICDP), often have increasingly important microbiology and geochemistry components (D'Hondt et al., 2007; Orcutt et al., 2014). Microbiology and geochemistry samples collected from cores present special challenges for scientists carrying out this sampling, as samples are time sensitive, with properties that change rapidly following recovery as a consequence of surface temperature, atmospheric composition, pressure, and other properties, differing from in situ conditions (Lin et al., 2010; Mills et al., 2012). Samples must be removed from the core (generally as whole rounds), recorded, and preserved as quickly as possible following core recovery. In order to ensure that all sample requests are fulfilled and samples are preserved correctly while swiftly processing time-sensitive samples, a clear and straightforward sampling plan is vital. Such a sampling plan should clearly describe which samples need to be taken from each section expected from a given hole, so that when the core is ready for processing no time is wasted.

IODP Expedition 347 (Baltic Sea Paleoenvironment) included a significant microbiological shipboard sampling program. During the offshore phase, samples were collected for
27 separate sample requests for microbiological and geochemical analyses. Each of these sample requests had different handling instructions, including storage at -80 or $-20^{\circ} \mathrm{C}$, storage under a nitrogen atmosphere, and mixing with various chemical preservatives, including formaldehyde and glycerol solutions. Several holes were drilled at each site, with the final hole dedicated to subsampling for microbiology, meaning that data collected while drilling the first holes were used to determine the optimal sampling frequencies for each unit in the microbiology hole. Time for developing the sampling plan was thus limited, and with $3 \mathrm{~m}$ cores arriving on deck at an average rate of one per hour, the time available for subsampling and preserving each core was tightly restricted. To meet these challenges, a software tool called Corganiser was developed to enable the rapid creation and modification of whole-round sampling plans. Corganiser was designed to be sufficiently flexible for use on other platforms and expeditions with core and section lengths other than those used during Expedition 347.

This paper describes the input parameters and algorithm used to place samples within the sampling plan as well as the two implementations of Corganiser: web-based and command line. 


\section{How Corganiser works}

Corganiser is designed to produce a colour-coded diagram to guide processing of each core without the time-consuming, error-prone, and labour-intensive process of producing a diagram for each core manually.

\subsection{Data input}

To make a sampling plan for a hole, the user enters the length of the core to be sampled, the number of sections the core will be divided into, the unsampled length of the core (e.g. the length of the core catcher and any other depth intervals not sampled), and the total depth of the hole. For each sample request, the user can enter samples in two different ways: either as one-off samples taken at specific depths, or as a series of samples taken at regular intervals across a specific depth range. Each sample is given a length (i.e. $10 \mathrm{~cm}$ whole-round core) and a short text handling instruction (i.e. " $-80^{\circ} \mathrm{C}$ " or "anoxic $4{ }^{\circ} \mathrm{C}$ "). The user can also specify a starting depth and starting core number, meaning that a sampling plan can be made to cover a portion of a hole's entire depth. This is useful if a change in core length or section length is planned in the course of drilling, as a different sampling plan can be made for each core/section length configuration.

\subsection{Sample placement algorithm}

Samples are placed at the next-deepest section interface following the depth specified by the user. Samples are prioritised by stacking outwards from each section interface in the order that the sample requests are entered to keep them as close to one another and thus as easily comparable to each other as possible. Sample requests under the same sample request number are placed adjacent to each other. Samples are generally not placed in Sect. 1, as the top of the core is usually the most disturbed part of the core. Samples are only placed in Sect. 1 when samples have a repeating depth interval equal to the length of one section or less, as decisions about the usefulness of these samples can be made on a case-by-case basis. Samples are not placed at the precise depth specified by the user's input for two reasons: (a) this would not avoid samples overlapping with one another and (b) whole-round cores are typically sampled from the section edges inwards to preserve the longest possible segments of each section for non-time-sensitive analyses. If too many samples are placed in a given target section (i.e. potentially overlapping samples) then an error message will be generated. It will be evident from the program's output which sample request was one too many for that particular section, allowing the operator to re-design the sampling plan with adjusted target depths.

\subsection{Sampling plan output}

The sampling plan is produced as a colour-coded diagram, with one or more pages for each core and at most three sections shown on each page. Each section has a centimetre ruler to its left to aid in slicing the section accurately. Handling instructions for each sample are listed down the right-hand side of each section. A different colour is used for each sample request number, with a key on the right-hand side of the page showing which sample request each colour corresponds to.

\section{Implementation}

Corganiser has been written in the Python programming language using the ReportLab package (ReportLab Europe Ltd, London, UK), for drawing diagrams in PDF format. Corganiser can be used in two different ways: via a graphical webbased implementation and a command-line-based implementation (Fig. 1).

\subsection{Web-based implementation}

In the web-based implementation, the user inputs data using an HTML form. This form is dynamically updated based on the user's inputs to include fields for as many sample requests and samples as necessary. Submitting the form produces two output files: the PDF sampling plan file in A4 format ready for printing and use, and a Corganiser file (a ".cor" file) in a custom text-based format containing all the information entered into the HTML form. The ".cor" file can be saved on the user's computer and re-uploaded to the server for editing at a future time. The web-based implementation is intended for users unfamiliar with using software tools from the command line and who have access to the internet during the drilling project. The Corganiser web application is currently hosted at Aarhus University in Denmark and can be accessed via the URL http://130.226.247.137/. The source code for this implementation is available at https: //github.com/ianpgm/Corganiser.

\subsection{Command-line implementation}

Corganiser is also available in a command-line implementation. Here the user executes a Python script with a ".cor" input file to generate a PDF file output. The ".cor" file can be produced either by the web-based Corganiser service, modified from a file produced on the web, or created by the user themselves as a text file - the correct notation for writing a ".cor" file is included in the Corganiser manual. The command line implementation will work on any operating system with Python and ReportLab, including Windows, MacOS X, and GNU/Linux. It has the advantage of working independently of an internet connection, but the disadvantage of requiring an operator familiar with executing Python scripts from the command line. The scripts for the 


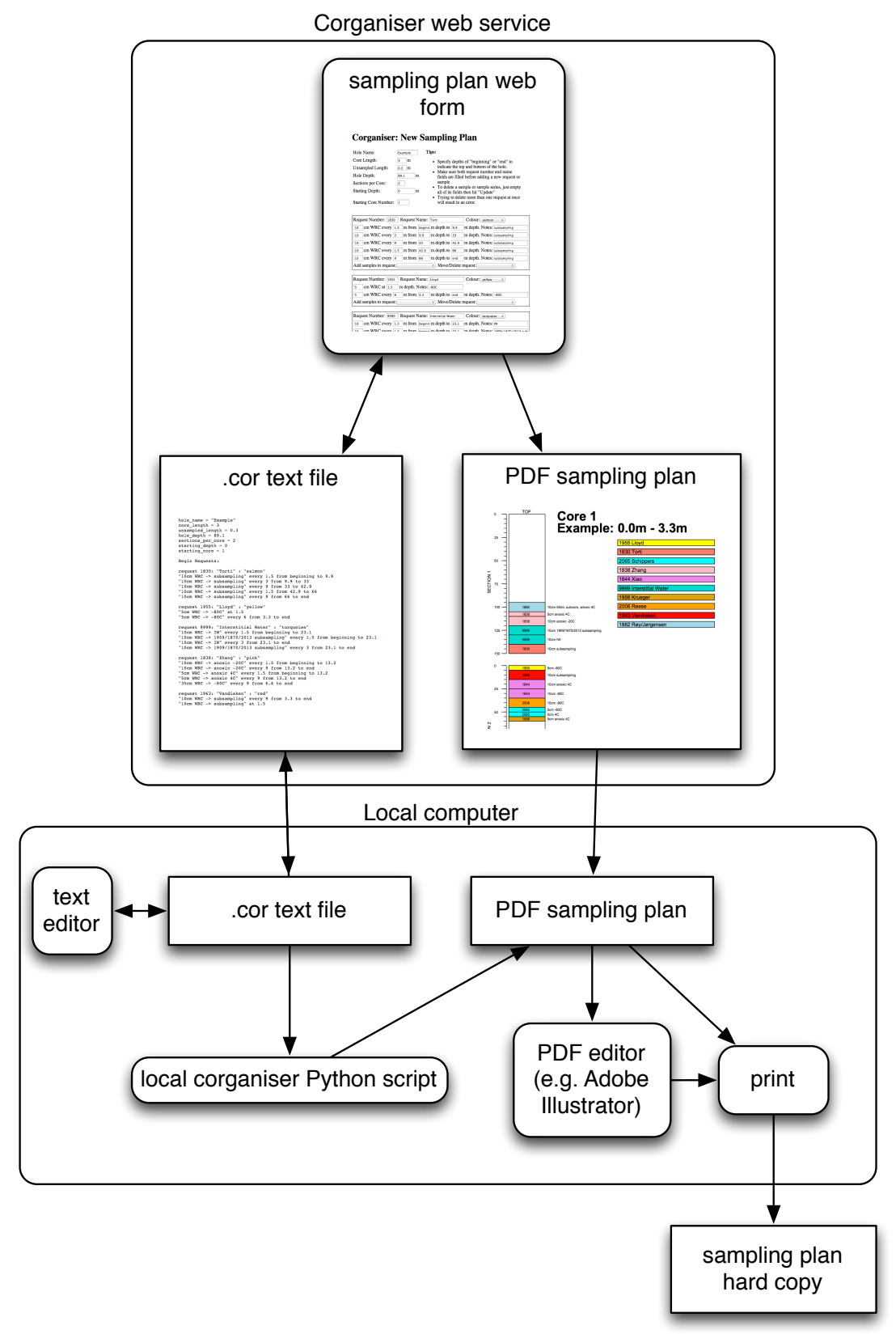

Figure 1. Diagram displaying how the web-based and desktop versions of Corganiser can be used to generate a sampling plan.

command-line implementation of Corganiser can be downloaded from https://github.com/ianpgm/Corganiser.

\subsection{Further modification of Corganiser output}

PDF files generated by Corganiser can be edited by any software capable of editing vector graphics in PDF files, such as Adobe Illustrator. Section diagrams can be modified and extra annotations can be added manually if sampling plans require changes beyond Corganiser's core capabilities.

\section{Limitations}

\subsection{Cut-off syringe sampling}

Corganiser does not plan the organisation of sampling with cut-off syringes, as the arrangement of such syringes in a core cross section is a much more complex problem and impacted by the individual needs of the researchers carrying out sampling, the nature of the sediment, and the tools available to the researchers. During IODP Expedition 347 syringe sampling was manually planned, with space made for syringe 
sampling in the Corganiser plan using a "syringe" sample request spacer.

\subsection{Maximum sampling frequency}

For each sample type, Corganiser is designed to work with a maximum of one sample per section. Attempts to enter a higher sampling frequency (a sampling interval shorter than the section length) will result in samples from the same requester adjacent to one another. This is an intentional limitation, following the practice of sampling whole-round cores from section ends only. If a higher sampling frequency than once per section is required, then the simplest way of planning this is to increase the number of sections per core. For example, if a sample requester requests one sample every $0.5 \mathrm{~m}$ for a hole with planned section lengths of $1.5 \mathrm{~m}$, the planned section length should be decreased to $0.5 \mathrm{~m}$.

\subsection{Changes to the plan following core collection}

The sampling plan produced by Corganiser is of course an idealised view of how the samples will be taken. Suboptimal core recovery, disturbed cores, lithologies poorly suited to microbial/geochemical sampling, and a myriad of other factors will help determine the best sampling strategy. In such cases handwritten annotations to the printed sampling plan will help to keep data entry, label printing, and sampling organised.

\section{Conclusions}

Corganiser proved itself a useful tool during IODP Expedition 347, helping to streamline the collection of whole-round samples with a printed, colour-coded plan produced several hours before the drilling of each microbiology hole commenced. This short timespan for generating sampling plans meant that the plans could be guided by data generated offshore from other holes drilled at the same site. Corganiser is now available as an easy-to-use web application suitable for preparing sampling plans during future scientific drilling projects with extensive sampling of whole rounds for microbiological and geochemical analyses.
Acknowledgements. Thanks to all ESO staff and science party members from Expedition 347, in particular Expedition Project Managers and the offshore microbiologists, for close cooperation and feedback in the development of Corganiser. Thanks to Tim Engelhardt for helpful comments regarding the manuscript. The research underlying this article has been co-funded by the Danish National Research Foundation and the European Research Council under the European Union's Seventh Framework Programme (FP/2007-2013)/ERC grant agreement no. 294200.

Edited by: U. Harms

Reviewed by: F. Inagaki and one anonymous referee

\section{References}

D’Hondt, S., Inagaki, F., Ferdelman, T., Barker Jørgensen, B., Kato, K., Kemp, P., Sobecky, P., Sogin, M., and Takai, K.: Exploring Subseafloor Life with the Integrated Ocean Drilling Program, Sci. Dril., 5, 26-37, doi:10.5194/sd-5-26-2007, 2007.

Lin, Y.-S., Biddle, J. F., Lipp, J. S., Orcutt, B. N., Holler, T., Teske, A., and Hinrichs, K.-U.: Effect of Storage Conditions on Archaeal and Bacterial Communities in Subsurface Marine Sediments, Geomicrobio. J., 27, 261-272, doi:10.1080/01490450903410423, 2010.

Mills, H. J., Reese, B. K., and St Peter, C.: Characterization of microbial population shifts during sample storage, Front. Microbiol., 3, 49, doi:10.3389/fmicb.2012.00049, 2012.

Orcutt, B. N., LaRowe, D. E., Lloyd, K. G., Mills, H., Orsi, W., Reese, B. K., Sauvage, J., Huber, J. A., and Amend, J.: IODP Deep Biosphere Research Workshop report - a synthesis of recent investigations, and discussion of new research questions and drilling targets, Sci. Dril., 17, 61-66, doi:10.5194/sd-17-612014, 2014. 